\title{
Permeation of iodide from iodine-enriched yeast through porcine intestine*
}

\author{
Florian Ryszka', Barbara Dolińska',2匹, Michał Zieliński', Dagmara Chyra' and \\ Zbigniew Dobrzański ${ }^{3}$
}

1Pharmaceutical Research and Production Plant "Biochefa", Sosnowiec, Poland; 2Department of Applied Pharmacy and Drug Technology, Medical University of Silesia, Sosnowiec, Poland; ${ }^{3}$ Department of Animal Hygiene and Animal Welfare, Wrocław University of Environmental and Life Sciences, Wrocław, Poland

lodine deficiency is a common phenomenon, threatening the whole global human population. Recommended daily intake of iodine is $150 \mu \mathrm{g}$ for adults and $250 \mu \mathrm{g}$ for pregnant and breastfeeding women. About $50 \%$ of human population can be at risk of moderate iodine deficiency. Due to this fact, increased iodine supplementation is recommended, through intake of iodized mineral water and salt iodization. The aim of this study was to investigate permeation and absorption of iodide from iodine bioplex (experimental group) in comparison with potassium iodide (controls). Permeation and absorption processes were investigated in vitro using a porcine intestine. The experimental model was based on a standard Franz diffusion cell (FD-Cell). The iodine bioplex was produced using Saccharomyces cerevisiae yeast and whey powder: iodine content - $388 \mu \mathrm{g} / \mathrm{g}$, total protein $28.5 \%$, total fat $-0.9 \%$., glutamic acid $-41.2 \%$, asparaginic acid $-29.4 \%$, lysine $-24.8 \%$; purchased from: F.Z.N.P. Biochefa, Sosnowiec, Poland. Potassium iodide was used as controls, at $388 \mu \mathrm{g}$ iodine concentration, which was the same as in iodine-enriched yeast bioplex. A statistically significant increase in iodide permeation was observed for iodine-enriched yeast bioplex in comparison with controls - potassium iodide. After $5 \mathrm{~h}$ the total amount of permeated iodide from iodine-enriched yeast bioplex was $85 \%$, which is $\sim 2$-fold higher than controls - $37 \%$. lodide absorption was by contrast statistically significantly higher in controls $-7.3 \%$, in comparison with $4.5 \%$ in experimental group with iodine-enriched yeast bioplex. Presented results show that iodide permeation process dominates over absorption in case of iodine-enriched yeast bioplex.

Key words: lodide, bioplex, yeast, permeation

Received: 06 September, 2013; revised: 03 December, 2013; accepted: 09 December, 2013; available on-line: 20 December, 2013

\section{INTRODUCTION}

Iodine is a crucial microelement and plays a key role in appropriate brain development during embriogenesis. Securing a stable deliver of a daily dose is important in all age groups, especially in pregnant and breast-feeding women. The recommended daily intake is $150 \mu \mathrm{g}$ for adults and $250 \mu \mathrm{g}$ for pregnant and breast-feeding women. Iodine deficiency is a common phenomenon, which threatens the whole global population. About $50 \%$ of world population might be mildly iodine deficient (Melse-Boonstra \& Jaiswal, 2010; Zimmermann,
2010). Severe iodine deficiency is a serious threat for highland and inland populations, for whom sea-derived food products, being natural iodine carriers, are not easily available (Kurosad et al., 2005). Iodine deficiency is a serious problem not only in developing, but also for industrialized countries (Andersson et al., 2010). Therefore, iodine supplementation by supplying iodine-containing mineral water and iodized salt is inevitable. Nevertheless, iodized salt as a main carrier of iodine in the diet has some major disadvantages. One of these drawbacks is the fact, that iodized salt is very vulnerable to storage conditions: in hot and humid climate much iodine is lost from the salt. In developing countries salt is often packaged using jute or woven polypropylene bags, which allow water permeation and consequent iodine loss. Another limitation comes from the WHO recommendations concerning lowering salt consumption as a method of blood hypertension prevention. Having decreasing salt consumption trend in mind, the role of table salt as a main iodine carrier in human diet should be reconsidered. Changing eating habits and still increasing consumption of processed food, which according to local regulations does not undergo mandatory iodization, impairs iodine supplementation (WHO, 2008; Szybiński, 2009; Szybiński \& Jarosz, 2010). Presented drawbacks suggest that a strong need for developing novel dietary supplements containing iodine does exist.

The developed yest based iodine bioplex, manufactured using whey and Saccharomyces cerevisiae baker's yeast can be a novel iodine carrier. The bioplex was proved effective as iodine source for laying hens and hen's egg iodine fortification (Dolińska et al., 2010; Dolińska et al., 2011; Dolińska et al., 2012). The aim of presented study was to investigate the process of permeation and absorption of iodide from iodine-enriched yeast bioplex (studied group) in porcine intestine in comparison with potassium iodide (controls). The absorption and permeation through isolated porcine intestine were studied under in vitro conditions. The scientific model utilized a standard Franz diffusion cell (FD-Cell) (Franz, 1975).

\section{MATERIALS AND METHODS}

Materials. The biological iodine complex derived from Saccharomyces cerevisiae grown on whey was pur-

e-mail: mzielinski@biochefa.pl

*Presented at the 5th Central European Congress of Life Sciences „EUROBIOTECH 2013", Kraków, Poland.

Abbreviations: FD-Cell, Franz diffusion cell 
chased from the Pharmaceutical Research and Production Plant "Biochefa," in Sosnowiec, Poland. The iodineenriched yeast had an iodine concentration of $388 \mathrm{ppm}$ with $28.5 \%$ total protein, $0.9 \%$ fat, $41.2 \%$ glutamic acid, $29.4 \%$ aspartic acid, and 24.8\% lysine (Dolińska et al., 2010).

— Potassium iodide — p.p.a. POCh, Gliwice, Sosnowiec

— Sodium chloride — p.p.a. POCh, Gliwice, Sosnowiec

- Hydrochloric acid - p.p.a. POCh, Gliwice, Sosnowiec

- Porcine intestine.

Fresh porcine intestinal specimens were obtained and preserved according to transplantation procedures. The intestine samples were excised from 6-months-old pigs, weighing $100 \pm 2 \mathrm{~kg}$. After collection, the veins were washed with saline until absorbance was $<0.02$ at $278 \mathrm{~nm}$. The samples were further preserved at $-18^{\circ} \mathrm{C}$. Before the experiment, the samples were thawed and washed with saline (Toledo-Pereyra et al., 2010).

Methods. Experimental. Permeation of iodide from iodine-enriched yeast bioplex through porcine intestine was studied. The experiment was carried out for $5 \mathrm{~h}$, with $30 \mathrm{~min}$ sampling interval. The experiments were conducted on a standard FD-Cell (Franz, 1975). The cell had two identical cells with flat ground connectors, each of $2.0 \mathrm{ml}$ capacity and fitted with an inlet/outlet. One of the chambers acted as a donor compartment (D), and second as an acceptor compartment (A). The two compartments were separated by an intestine sample trimmed to the shape of a circle to act as a natural membrane. The vein specimen was facing the donor with its internal side and acceptor with its external surface. A "side-byside" methodology was applied, where donor and acceptor cells were leveled horizontally.

The diffusion cell is presented in Fig. 1.

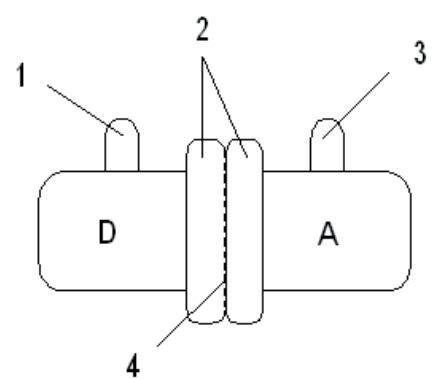

Figure 1. Standard Franz diffusion cell.

D, donor cell; A, acceptor cell; 1, intel channel; 2, flat ground connector; $\mathbf{3}$, outlet channel; $\mathbf{4}$, porcine vein.

The donor chamber (D) was filled with $2.0 \mathrm{~mL}$ of iodine-enriched yeast bioplex dissolved in $0.1 \mathrm{M} \mathrm{HCl}$, which simulated gastric acid $2.0 \mathrm{~mL}$ of the fluid contained $388 \mu \mathrm{g}$ of iodine.

Acceptor chamber (A) contained $2.0 \mathrm{~mL}$ of saline, which simulated peritoneal fluid.

Controls contained potassium iodide at a concentration of $388 \mu \mathrm{g}$ iodine. The experiment was carried out under the same protocol as for the studied group.

Permeation was calculated as the amount of substance, which was transported across biological membrane (isolated intestine) from donor chamber (D) to ac- ceptor chamber (A) in time relative to initial substance amount in donor chamber in $\mathrm{t}=0$.

Permeability $=C_{t} \times 100 \% / C_{o},[\%]$

$\mathrm{C}_{t}$ - concentration of permeated iodine after time $\mathrm{t}$ $[\mathrm{g} / \mathrm{l}], \mathrm{C}_{\mathrm{o}}$ - initial iodine concentration in time $\left.\mathrm{t}_{0}[\mathrm{~g} / \mathrm{l}]\right)$.

Absorption was calculated as an amount of iodine being the difference between initial donor chamber (D) amount and sum of the overall amount of iodine measured in acceptor chamber (A) in $5 \mathrm{~h}$ and residual donor (D) amount after $5 \mathrm{~h}$.

Absorption $=\left[\left(\mathrm{C}_{\mathrm{o}}\left(\mathrm{C}_{5 \mathrm{~h}}+\mathrm{C}_{\mathrm{DR}}\right)\right] \times 100 \% / \mathrm{C}_{\mathrm{o}},[\%]\right.$

$\mathrm{C}_{5 \mathrm{~h}}$ - concentration of permeated iodine after time $\mathrm{t}$ $=5 \mathrm{~h}[\mathrm{~g} / \mathrm{l}], \mathrm{C}_{\mathrm{o}}$ - initial iodine concentration in time $\mathrm{t}_{0}$ $[\mathrm{g} / 1]), \mathrm{C}_{\mathrm{DR}}$ - residual donor iodine concentration after $5 \mathrm{~h}[\mathrm{~g} / \mathrm{l}]$

Iodide concentration. The iodine concentration was measured using an ion-specific iodide electrode type EI-01, purchased from Hydromet, Poland. The electrode was calibrated using a series of iodide solutions of known concentrations. The dependence between the molar (M) iodide concentration, and the value in the display was given by a regression equation:

$\mathrm{y}=4 \mathrm{E} 13 \mathrm{e}^{2,2031 \mathrm{x}}$

where $\mathrm{x}$ is the value in the display and $\mathrm{y}$ is the concentration of iodide (in mole per liter). The fit of the equation to the experimental points was close to unity, $\left(\mathrm{R}^{2}=\right.$ 0.9999).

Statistical treatment of the results. The results were calculated as mean values ( \pm \pm S.D.) of seven replicates. The statistical analysis was carried out using the Excel (Microsoft) and Statistica (StatSoft Inc.) software: Pharmaceutical Analysis, Drug Release Profile. Profiles were compared using Weibull distribution methodology with subsequent ANOVA test for studied bioplex versus controls with $p<0.05$. Weibull distribution method is a model-dependent method and is approved by FDA for pharmaceutical analyzes.

\section{RESULTS}

In the study, we investigated permeation and absorption of iodide from iodine-enriched yeast bioplex in isolated porcine intestine during $5 \mathrm{~h}$ of experiment in comparison with controls — potassium iodide. Statistically significant differences were observed in permeation and absorption of iodide from iodine-enriched yeast bioplex relative to controls. Iodine permeation after $5 \mathrm{~h}$ was $84.89 \%$ in studied group, compared to $36.99 \%$ in controls. Iodide permeation is about 2.3-fold higher for iodine-enriched yeast relative to controls. The difference is statistically significant at $p<0.05$. Absorption is statistically significantly higher for controls: $7.33 \%$ in comparison with $4.53 \%$ for studied group.

Results showing total absorption and permeation after $5 \mathrm{~h}$ are presented in Fig. 2.

Figure 3 shows permeation profiles of iodide from iodine-enriched yeast bioplex relative to controls. A distinctive peak can be observed between 0 to $3 \mathrm{~h}$ with a maximum at 1.5 to $2 \mathrm{~h}$. In 0 to $3 \mathrm{~h}$ time span the permeation of iodide is significantly lower for potassium iodide. Comparison of permeation profiles using Weibull method showed statistically significant differences $(p=0.000018)$. 


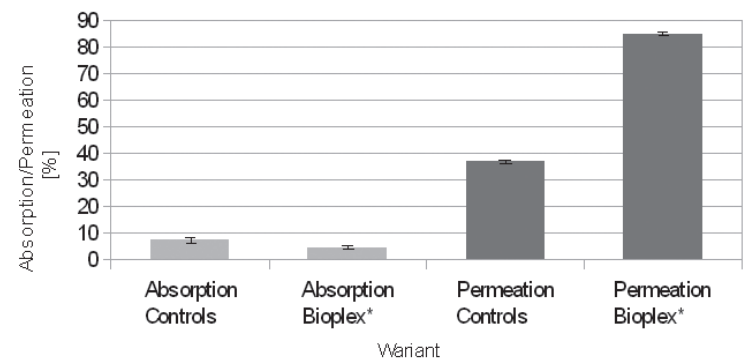

Figure 2. Absorption and permeation of iodide through porcine intestine [\%].

*Statistically significant difference relative to controls $(p<0.05)$.

\section{DISCUSSION}

Developing novel iodine carriers for human nutrition is a vital concern. According to WHO recommendations novel iodine carriers should be implemented in order to substitute iodized salt (Szybiński\&Jarosz, 2010). Some of proposed solutions like iodized mineral water and cooking oils present certain disadvantages. The consumption of these products varies greatly in different regions and even within small populations. Therefore, iodine dietary supplements should be proposed. Iodine-enriched yeast bioplex contains an organic iodine source. Organic forms of microelements often show better bioavailability than traditional inorganic (mineral) compounds. Presented results suggest, that iodine permeation through the porcine intestine dominates over absorption. Statistically significantly higher permeation is observed for iodineenriched yeast bioplex in comparison with controls. A different permeation profile during $5 \mathrm{~h}$ of experiment indicates, that a different transport mechanism should be expected for the bioplex than for inorganic iodide. Only few literature sources report organic iodine compounds like iodine-containing linear hydrocarbons (for example: iodomethane) found in organic material (Edmonds \& Morita, 1998). High values of iodine permeation observed for iodine-enriched yeast can suggest that iodine is bound to peptides and proteins. The protein is partially hydrolyzed, so it contains oligopeptides. Organic bound iodine can undergo transportation mediated by amino acid and peptide transporters. Inorganic iodine from potassium iodide is transported with the aid of natrium-iodide symporter located in the intestine wall (Nicola et al., 2009).

Transport mechanisms for organic bound iodine should be considered more efficiently than symporter mediated transport, because transport mechanisms for basic nutrients, like amino acids, do not get easily saturated and, assure effective transport. The transportation of organic bound iodine can be compared to amino acid chelates, being a novel dietary supplements, for example: magnesium diglycinate. Therefore, having taken high permeation of iodide from iodine-enriched yeast bioplex into consideration, effective supplementation can be expected in humans and animals offered iodine-enriched yeast.

An obvious need for development of novel iodine supplementation strategies creates a possibility for investigating novel organic bound based supplements. Organic bound chromium or selenium from enriched baker's yeast are commonly accepted and used over many years. They offer excellent bioavailability with very low risk of causing side effects (Schrauzer, 2006; Zetic et al., 2001). Iodine-enriched yeast is a promising novel iodine supple-

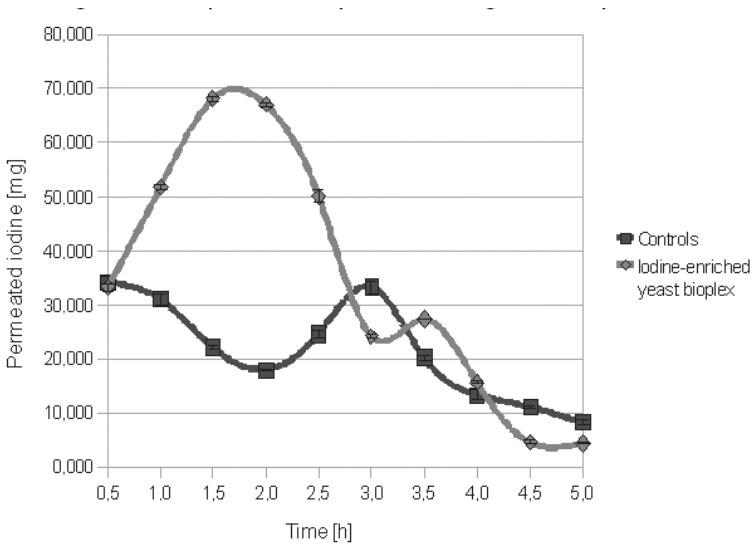

Figure 3. lodide permeation profiles during $5 \mathrm{~h}$ of experiment.

ment aimed at elimination of iodine deficiency, which is a continuing threat to both industrialized and developing societies.

\section{REFERENCES}

Andersson M, De Benoist B, Rogers L (2010) Epidemiology of iodine deficiency: Salt iodisation and iodine status. Best Practice \& Research Clinical Endocrinology \& Metabolism 24: 1-11.

Dolińska B, Opaliński S, Zieliński M, Chojnacka K, Dobrzański Z, Ryszka F(2011) Iodine concentration in fodder influences the dynamics of iodine levels in hen's egg components. Biol Trace Elem Res 144: 747-752.

Dolińska B, Zieliński M, Dobrzański Z, Chojnacka K, Opaliński S, Ryszka F. (2012) Influence of incubation conditions on hydrolysis efficiency and iodine enrichment in baker's yeast. Biol Trace Elem Res 147: 354-358.

Dolińska B, Zieliński M, Opaliński S, Korczyński M, Dobrzański Z, Ryszka F (2010) Optimization of the conditions of iodine incorporation to Saccharomyces cerevisiae yeast. Przem Chem 90: 174-179.

Edmonds J, Morita M. (1998) The determination of iodine species in environmental and biological samples. Pure \& Appl Chem 70: 5671584.

Franz T. (1975) Percutaneus absorption and the relevance of in vitro data. I Invest Derm 64: 190-195.

Kurosad A, Nicpoń J, Kubiak K, Jankowski M, Kungl K (2005) Iodinnutrition. Adv Clin Exp Med 14: 1019-1025.

Melse-Boonstra A, Jaiswal N (2010)Iodine deficiency in pragnancy, infancy and childhood and its consequences for brain development. Best Practice \& Research Clinical Endocrinology \& Metabolism 24: 29-38.

Nicola J, Basquin C, Portulano C, Reyna-Neyra A, Paroder M, Carrasco (2009) N: The Na+/I+ symporter mediates active iodide uptake in the intestine. Am J Physiol Cell Physiol 296: 654-662.

Schrauzer G (2006) Selenium yeast: Composition, quality, analysis and safety. Pure Appl Chem 78: 105-109.

Szybiński Z (2009) Iodine prophylaxis in Poland in the lights of the WHO recommendation on reduction of the daily salt intake. Pediatr Endocrino Diabetes Metab 15: 103-107.

Szybiński Z, Jarosz M (2010) Iodine-deficiency prophylaxis and the restriction of salt consumption — a 21-st century challenge. Pol J Endocrinol 61: 135-140.

Toledo-Pereyra L, Lopez-Neblina F, Toledo A (2010) Organ freezing. Organ preservation for transplantation. 3-rd Landes Biosciences, Austin.

World Health Organization (2008) Salt as a vebicle for fortification. Report of a WHO expert consultation. Geneva: World Health Organization: $1-27$.

Zetic V et al. (2001) Chromium uptake by Saccharomyces cerevisiae and isolation of glucose tolerance factor from yeast biomass. $J$ Biosci 26: $217-223$

Zimmermann M (2010) Symposium on 'Geographical and geological influence on nutrition': Iodine deficiency in industrialised countries. Proc Nutr Soc 69: 133-143. 